\title{
LAS RELACIONES FISCALES INTERGUBERNAMENTALES Una aproximación al contexto jurídico de la tributación local en México
}

\author{
Intergovernmental fiscal relations \\ An approach to the legal context of local taxation in Mexico
}

Gloria María Plascencia de la Torre*

Eduardo Méndez Aguilar ${ }^{* *}$

Sumario:

1. Presentación. 2. Conceptos base finanzas públicas. 3. Hacienda pública. 4. Potestad tributaria. 5. La hacienda municipal en la legislación federal. 6. Constitución Política de los Estados Unidos Mexicanos. 7. Ley de Coordinación Fiscal comentarios previos. 8. En la legislación estatal. 9. De la Hacienda y del patrimonio municipal. 10. Legislación municipal básica. 11 Conclusiones. 12. Bibliografía.

Resumen. El estudio parte de dos premisas: a) la Constitución es la Ley Suprema, que da origen a la organización de un Estado, por ser la expresión más completa de la soberanía popular, al definir los órganos y competencias de que estará dotado en sus diferentes órdenes de gobierno; $y$ b) en modelos de Estado Federal como el mexicano, es indispensable que sus órdenes de gobierno, hagan uso de la potestad recaudatoria que les corresponde, evitando que su actuación financiera sólo se limite a la aplicación del gasto. El artículo, es parte de un proyecto de investigación sobre hacienda pública municipal, en el que se pondera la importancia de la corresponsabilidad recaudatoria. Es una investigación documental y para su desarrollo se utiliza el método hipotético-deductivo.

Palabras clave: Constitución, Estado Federal, Hacienda Municipal, Coordinación Fiscal y Finanzas Públicas.

Abstract. The study is based on two premises: to) the Constitution is the Supreme Law, which gives rise to the Organization of a State, for being the most complete expression of popular sovereignty, to identify the bodies and competencies that will be equipped with different orders of Government; and b) in the Mexican Federal State models, it is essential orders of Government, to make use of the Mexico powers theirs and avoiding that its financial performance only be limited to the implementation of expenditure. The article is part of a research project on municipal public finances, which ponders the importance of tax collection co-responsibility. A documentary and development research, the hypothetical-deductive method is used.

Key words: Constitution, Federal State, Local Finance, Public Finance and Taxation Coordination.

* Doctorado en Ciencias de la Administración. Maestría en Impuestos. Licenciatura en Contaduría Pública. Universidad de Guadalajara.

** Maestría en Impuestos. Contador Público. Licenciatura en Administración de Empresas. Universidad de Guadalajara. 


\section{PRESENTACIÓN}

La Constitución es la Ley Suprema, que da origen a la organización de un Estado, es la expresión más completa de la soberanía popular, al definir los órganos y competencias de que estará dotado en sus diferentes órdenes de gobierno, estableciendo obligaciones ${ }^{1}$ y reconociendo los derechos fundamentales de las personas. En ese sentido se expresa, $\mathrm{Pacheco}^{2}$ al señalar: "la supremacía constitucional la encontramos a mi criterio en los artículos 40, 41, 124, y 133 de la Constitución Política de los Estados Unidos Mexicanos (CPEUM).” Artículos que durante el desarrollo del artículo serán comentados recurrentemente.

Es bajo esta premisa, que la investigación inicia con el análisis —en lo conducente- de la CPEUM, como Ley Suprema y origen de las competencias de gobiernos locales, entre otras las relacionadas con las finanzas públicas. Para Flores " "las finanzas públicas tienen por objeto investigar las diversas maneras por cuyo medio el Estado o cualquier otro poder público se procura las riquezas materiales necesarias para su vida y su funcionamiento y también la forma en que estas riquezas serán utilizadas."

La exploración de competencias recaudatorias de recursos fiscales estatal y municipal, y su necesaria corresponsabilidad con la federación, se presentan como una de las asignaturas pendientes para la consolidación del sistema fiscal mexicano, para efecto de la exploración del modelo, se tomará como ejemplo la legislación fiscal del Estado de Jalisco, con el fin de ilustrar la regulación que los congresos locales realizan en materia hacendaria. Doctrinalmente por materia fiscal se entiende 4 "todo lo relativo a los ingresos del Estado provenientes de las contribuciones y a las relaciones entre el propio Estado y los particulares, considerados en su calidad de contribuyentes."

Margáin 5 por su parte señala: "materia fiscal es el conjunto de disposiciones legales y de principios de derecho público que regulan la actividad jurídica del fisco”. En fin, son muchas y muy variadas las definiciones que la doctrina en México genera sobre el tema sin que exista total coincidencia en ellas. En la reflexión sobre la legislación de los tres órdenes de gobierno, se considerarán los cuatro elementos de la hacienda pública -ingreso, gasto, deuda y patrimonio-. Para De la Garza ${ }^{6}$ hacienda pública es: "toda la vida económica de los entes públicos y en sentido estricto hace mención de los ingresos, pertenecientes y gastos de las entidades públicas.”

Como una primera aproximación a las limitaciones jurídicas de la hacienda municipal, es pertinente reconocer que bajo ninguna circunstancia, el municipio puede crear diretamente

\footnotetext{
1 En relación con las obligaciones, Faya señala: los habitantes de una nación, en ciertas circunstancias, están obligados al pago de determinados impuestos, sin que los ciudadanos puedan exigir una contraprestación directa de parte del Estado.

* Maestría en Impuestos, Contador Público, Licenciatura en Administración de Empresas, Universidad de Guadalajara.

** Doctorado en Ciencias de la Administración, Maestría en Impuestos, Licenciatura en Contaduría Pública, Universidad de Guadalajara.

${ }^{2}$ Pacheco, Guillermo, Supremacía Constitucional y Federalismo Jurídico, México, Editorial Porrúa, 2001, p. 73.

${ }^{3}$ Flores, Ernesto, Elementos de Finanzas Públicas Mexicanas, México, Editorial Porrúa, 1991, p. 10.

${ }^{4}$ Rodríguez, Raúl, Derecho Fiscal, México, Editorial Harla, 1990, p. 11.

${ }^{5}$ Margáin, Emilio, Introducción al Estudio del Derecho Tributario Mexicano, 4 a edición, San Luis Potosí, Universidad Autónoma de San Luis Potosí, 1977, p. 22.

${ }^{6}$ De la Garza, Sergio, Derecho Financiero Mexicano, 8a. edición, México, Editorial Porrúa, 1978, p. 198. 
para sí impuesto alguno, por carecer de poder tributario, tanto originario, ${ }^{7}$ como derivado, ${ }^{8}$ tomando en cuenta que éste no tiene un poder legislativo en sentido estricto, dado que el ayuntamiento como órgano materialmente legislador, se circunscribe a la expedición de disposiciones reglamentarias, por corresponder esta facultad constitucionalmente, a la Entidad Federativa que pertenezca. Esta teoría queda confirmada por la Suprema Corte de Justicia de la Nación (SCJN) a través de la jurisprudencia 963, foja 1564, Vol. II, Apéndice 1917-1988, que en lo conducente señala: "IMPUESTOS MUNICIPALES. Los decretados por los Ayuntamientos y no por las legislaturas no tienen el carácter de leyes, y hacerlos efectivos importa una violación constitucional".

El Congreso del Estado al que pertenece el municipio, es el facultado para establecer los ingresos fiscales que la hacienda pública local deberá recaudar. El municipio tiene autonomía política y administrativa, pero carece de facultad para establecer contribuciones, por lo que no puede determinar las que formarán su hacienda. De acuerdo con los ordenamientos mencionados con anterioridad, los municipios la administrarán libremente; pero son las legislaturas de cada Estado las que aprueban sus leyes de ingresos - los presupuestos de egresos los autorizan los respectivos ayuntamientos con base en sus ingresos disponibles-y revisan sus cuentas públicas.

\section{CONCEPTOS BASEFINANZAS PÚBLICAS}

Además de la posición sobre lo que debemos entender por finanzas públicas que hace Flores Zavala, es pertinente reconocer que el vocablo es más un término económico que jurídico y en este sentido Arriaga ${ }^{9}$ señala: "las finanzas públicas constituyen una herramienta importante para la consecución de los objetivos de la política económica, pero si no se encuentra debidamente coordinada con instrumentos, como: el área monetaria, crediticia, desempleo, precios y tarifas, agropecuaria, industrial y salarial, no participarán éstas de manera adecuada”.

\section{HACIENDA PÚBLICA}

El origen de la hacienda pública, coincide con el surgimiento de la economía como disciplina científica en 1776, con la publicación del libro de Adam Smith La riqueza de las naciones. En relación con su significado doctrinal, Rendón ${ }^{10}$ señala: "la connotación de hacienda en su acepción más amplia, es el conjunto de bienes y medios de producción que permiten el abastecimiento y que integran el haber de una comunidad". Es importante hacer notar, que con frecuencia se cae en el error jurídico, de tomar el vocablo fisco como sinónimo de hacienda o erario público, en relación con esto, el propio De la Garza ${ }^{11}$ afirma que "tomarlos como sinónimos, sería tanto como equiparar, una de las partes con el todo, y precisa, fisco es sólo la parte de la hacienda pública, encargada de la recaudación".

\footnotetext{
7 Se dice que el poder tributario es originario cuando surge de la Constitución y por tanto no se recibe de ninguna otra entidad. Tal es el caso de la Federación y de las Entidades Federativas en México donde ambas tienen poder tributario de origen por así disponerlo la Constitución Federal.

${ }^{8}$ Poder tributario derivado es el que la entidad política posee, porque le ha sido trasmitido por otra que tiene poder originario, situación no común en México.

${ }^{9}$ Arriaga, Enrique, Finanzas Públicas de México, México, Instituto Politécnico Nacional, 1992, p. 5.

${ }^{10}$ Rendón Huerta, Teresita, Derecho Municipal, Tercera edición, México, Editorial Porrúa, 2005, p. 294.

${ }^{11}$ De la Garza, Sergio, Derecho Financiero Mexicano, 8va edición, México, Editorial Porrúa, 1978, p. 52.
} 
Para, Flores ${ }^{12}$ la hacienda pública es el conjunto de bienes que una entidad pública -Federación, Estados, Municipios- posee en un momento dado para la realización de sus atribuciones, así como de las deudas que son a su cargo, por el mismo motivo, fisco en voz de Flores es, -como ya se comentó- sólo la parte de la hacienda pública, encargada de la recaudación. Según refiere Ortega ${ }^{13}$ los bienes que mantienen a la hacienda pública, y que hace referencia la definición anterior, están conformados por: contribuciones, deuda y patrimonio.

Los criterios que prevalecen en México, en relación con la hacienda pública, Ortega señala, "las actividades financieras del Estado, es decir, aquéllas que tienden a obtener ingresos, realizar gastos y gestionar los bienes patrimoniales del Estado, están regidas por criterios esencialmente políticos y no por criterios económicos, ello en atención tanto a los fines que tratan de satisfacer, como al carácter de los entes que tienen constitucionalmente encomendado tales tareas".

\section{POTESTAD TRIBUTARIA}

Sobre esta expresión, no existe uniformidad de criterios doctrinales para definirla, algunos juristas la identifican como poder impositivo, por ejemplo: Quintana y Rojas, ${ }^{14}$ De La Garza, ${ }^{15}$ Giuliani, ${ }^{16}$ Martín y Rodríguez. ${ }^{17}$ Otros la llaman poder tributario, también se le conoce como supremacía tributaria, soberanía fiscal o potestad tributaria, en voz de, Díaz en: Estudio monográfico acerca de la autonomía y conceptualización del Derecho Financiero, Público o Fiscal, Tribunal Fiscal de la Federación, cuarenta y cinco años al servicio de México. Tomo I, p. 277. Potestad tributaria es el vocablo que resulta más atinado, atendiendo a su significado jurídico-gramatical, por lo que, con base a lo anterior en México se puede definir, como la atribución legal que ejerce el Estado a través del poder legislativo, para establecer las contribuciones necesarias para solventar el gasto publico. ${ }^{18}$

\section{LA HACIENDA MUNICIPAL EN LA LEGISLACIÓN FEDERAL}

En materia de ingresos públicos municipales, existen muchos y muy diversos ordenamientos, que directa o indirectamente inciden en su hacienda pública, pero son dos los que por su influencia e importancia se analizarán:

- La Constitución Política de los Estados Unidos Mexicanos; y

- La Ley de Coordinación Fiscal.

\footnotetext{
${ }^{12}$ Flores, Ernesto, Elementos de Finanzas Públicas Mexicanas, México, Editorial Porrúa, 1991, p. 20.

${ }^{13}$ Ortega, Juan, Primer Curso de Derecho Tributario Mexicano, México, Editorial Porrúa, 2004, p. 4.

${ }^{14}$ Quintana, Jesús y Rojas, Jorge, Derecho Tributario Mexicano, México, Editorial Trillas, 1997.

${ }^{15}$ De la Garza, Sergio, Derecho Financiero Mexicano, 8va edición, México, Editorial Porrúa, 1978.

${ }^{16}$ Giuliani, Carlos, Derecho Financiero, Buenos Aires, Editorial Depalma, 1977, Volumen I.

${ }^{17}$ Martín, José y Rodríguez, Guillermo, Derecho Tributario General, de Finanzas y Derecho Tributario, Argentina, Depalma, 1995.

${ }^{18}$ En todos los casos o enfoques conduce a un solo punto, definir la forma en que el Estado la utiliza para obtener recursos tributarios que le permitan solventar el gasto público, en uso de la soberanía que la Constitución le otorga, mediante el establecimiento de leyes tributarias
} 


\section{CONSTITUCIÓN POLÍTICA DE LOS ESTADOS UNIDOS MEXICANOS. ${ }^{19}$}

La Constitución Federal como fuente formal del derecho fiscal, en México es norma suprema por así establecerlo los artículos 133 y 41, en relación con el municipio, contempla derechos y obligaciones en diversos artículos, entre otros: El 2, 3, 21, 26, 27, 31, 36, 73, 79, 105, 108, $115,116,117,123,128$ y $130,{ }^{20}$ de los cuales sin seguir un orden numérico, sólo se comentarán las partes de aquellos que directa o indirectamente, tienen relación con el manejo de la hacienda pública municipal y la limitación de sus potestades.

Artículo 133. Esta Constitución, las leyes del Congreso de la Unión que emanen de ella y todos los Tratados que estén de acuerdo con la misma, celebrados y que se celebren por el Presidente de la República, con aprobación del Senado, serán la Ley Suprema de toda la Unión. Los jueces de cada Estado se arreglarán a dicha Constitución, leyes y tratados, a pesar de las disposiciones en contrario que pueda haber en las Constituciones o leyes de los Estados.

Artículo 41. El pueblo ejerce su soberanía por medio de los Poderes de la Unión, en los casos de la competencia de éstos, y por los de los Estados, en lo que toca a sus regímenes interiores, en los términos respectivamente establecidos por la presente Constitución Federal y las particulares de los Estados, las que en ningún caso podrán contravenir las estipulaciones del Pacto Federal.

Para, González ${ }^{21}$ en: Prologo a la obra Principios Tributarios Constitucionales:

"La influencia de la Constitución... es, si cabe, todavía más estrecha respecto al derecho tributario porque esta rama del derecho público no sólo encuentra en la Constitución la distribución y coordinación de las competencias tributarias entre los distintos poderes, sino también la regulación básica de los principios generales -igualdad, legalidad y seguridad jurídica- y específicos (capacidad contributiva, progresividad y no confiscatoriedad), que presiden la función tributaria del Estado tanto en su esfera normativa como en la aplicativa”.

En cuanto al origen de la obligación de los mexicanos de pagar contribuciones, a cualquiera de los tres órdenes de gobierno, surge a partir de lo establecido por el artículo 31-IV, por otra parte, la propia Carta Magna establece las atribuciones de los tres poderes de la Unión -Ejecutivo, Legislativo y Judicial-, y los limites jurisdiccionales de la Federación, Estados y Municipios en materia tributaria.

Artículo 31. Son obligaciones de los mexicanos:

\footnotetext{
${ }^{19}$ Para efectos del estudio, se consultaron diversas páginas de la Constitución Política de los Estados Unidos Mexicanos (2008), décimo primera edición. McGraw-Hill Interamericana.

${ }^{20}$ El texto constitucional utilizado en el presente trabajo, es el vigente hasta la reforma publicada en el Diario Oficial de la Federación (DOF) del 18 de junio de 2008.

${ }^{21}$ González, Eusebio, Prologo a la obra: Principios Tributarios Constitucionales, México, coedición UNAM, TFF, Ed. Universidad de Salamanca e instituto Cultural Domecq, 1989, p. 2.
} 
I, II, III,...

IV. Contribuir para los gastos públicos, así de la Federación, como del Distrito Federal o del Estado y Municipio en que residan, de la manera proporcional y equitativa que dispongan las leyes.

Aún cuando, según García ${ }^{22}$ no existe en la Constitución Federal, una línea que separe con exactitud la competencia que tienen la Federación y las Entidades Federativas, para imponer contribuciones. A pesar de esta dificultad, existen preceptos constitucionales que arrojan una visión panorámica al respecto. Apoyados en estas disposiciones, la SCJN ha sentado la jurisprudencia 56 de la primera parte del apendice1985 para aclarar el asunto. Dicha jurisprudencia en lo conducente señala:

- La Constitución General no opta por una delimitación de la competencia federal y estatal para establecer impuestos, sino que sigue un sistema complejo, cuyas premisas fundamentales son las siguientes: a) Concurrencia contributiva de la Federación y los Estados en la mayoría de las fuentes de ingresos (artículo 73, fracción VII y 124); b) Limitaciones a la facultad impositiva de los Estados mediante la reserva expresa y concreta de determinadas materias a la Federación (artículo 73, fracción XXIX); y c) Restricciones expresas a la potestad tributaria de los Estados (artículo 117, fracciones IV, V, VI y VII y 118).

- Es importante hacer notar, que en el art.31-IV, que existe intima relación -o condicionante- entre ingresos y gastos públicos, de suerte que no se pueden desvincular unos de los otros, porque se estaría cayendo en el terreno de la extrafiscalidad o violentando el principio de destino. Este principio exige que las contribuciones que los mexicanos están obligados a pagar a la federación estados y municipios donde residan se destinen al gasto público, requisito sin el cual según la Corte, se vulneran los postulados del articulo 31-IV de la CPEUM. Tesis que en lo conducente señala:

- El gasto público, doctrinaria y constitucionalmente tiene un sentido social y un alcance de interés colectivo; y es y será siempre gasto público, que el importe de lo recaudado por la federación, al través de los impuestos, derechos, productos y aprovechamientos, se destine a la satisfacción de las atribuciones del Estado relacionadas con las necesidades colectivas o sociales, o los servicios públicos. Séptima Época, Sala Auxiliar, Apéndice de 1995, Tomo: I, Parte HO, Tesis 367, p. 339.

Por otra parte, existe una obligación más de carácter patrimonial de los ciudadanos mexicanos, que por su importancia, en la correcta aplicación del impuesto a la propiedad inmobiliaria y por estar relacionada con lo establecido en la fracc. IV del 115, además de ser parte activa del objeto de estudio, de la presente investigación, se transcribe y comenta a continuación.

Artículo 36. Son obligaciones del ciudadano de la República:

I. Inscribirse en el catastro de la municipalidad, manifestando la propiedad que el mismo ciudadano tenga, la industria, profesión o trabajo de que subsista; así como también inscribirse en el Registro Nacional de Ciudadanos, en los términos que determinen las leyes.

\footnotetext{
${ }^{22}$ García, Agustín, 1998. Análisis Constitucional de los ámbitos de la federación, los estados y municipios, en: Obra conmemorativa de los 50 años del TFF, México, TFF, 1988, tomo V, p. 89.
} 


\section{II, III, IV, V...}

En México, —como queda señalado, en el texto del párrafo inmediato anterior- todo bien inmueble debe inscribirse en el catastro de la municipalidad a la cual pertenezca. La función catastral consiste en la identificación y registro de la propiedad, constituye la base para la integración del padrón de contribuyentes del impuesto predial. El catastro ha sido considerado como el eje central, sobre el cual se apoya la administración del impuesto predial, al descansar en éste, las funciones relativas a la identificación y registro de la propiedad inmobiliaria, así como aquellas que tienen por objeto fijar el valor de la misma.

\section{Para, Carral: ${ }^{23}$}

"el catastro fiscal es el registro público de los bienes inmuebles ubicados en una demarcación territorial específica y que contiene la localización de dichos inmuebles: límites, extensión, transferencias, nombre del actual propietario y de los anteriores y en general, los elementos necesarios para poder evaluarlos y aplicar las tarifas correspondientes a los gravámenes que recaen sobre los propietarios o poseedores de los referidos bienes inmuebles".

Como se puede corroborar con los argumentos anteriores, es con los tres órdenes de gobierno, que se debe contribuir para solventar su gasto público, de tal suerte, que se hace necesario examinar el art. 115 de la Carta Magna, para identificar dentro de las múltiples potestades del municipio, las que de carácter fiscal, le reconoce la Constitución Federal.

Artículo 115. Los Estados adoptarán, para su régimen interior, la forma de gobierno republicano, representativo, popular, teniendo como base de su división territorial y de su organización política y administrativa el Municipio Libre, conforme a las bases siguientes: I...

II. Los municipios estarán investidos de personalidad jurídica y manejarán su patrimonio conforme a la ley.

III...

El principio de libre administración de la hacienda municipal consignado en la siguiente fracción, cuyo contenido y alcance ha sido precisado por la SCJN en varias tesis jurisprudenciales (véase, por ejemplo, las tesis plenaria 5/2000, de rubro "HACIENDA MUNICIPAL Y LIBRE ADMINISTRACION HACENDARIA. SUS DIFERENCIAS. (ARTICULO 115, FRACCION IV, DE LA CONSTITUCION FEDERAL)"), es el principio de libre administración de la hacienda municipal, que asegura a los municipios la posibilidad de manejar, aplicar y priorizar libremente los recursos de que disponen para satisfacer sus necesidades públicas, sin que tengan que sufrir la injerencia de intereses ajenos en ese respecto. ${ }^{24}$

${ }^{23}$ Carral y de Teresa, Luis, Derecho notarial y derecho registral, 4 a edición, México, Editorial Porrúa, 1978, p. 76.

${ }^{24}$ El principio de libre administración de la hacienda municipal se proyecta sobre parte de los recursos que integran la hacienda municipal y no sobre la totalidad de los mismos. 
Otro principio ${ }^{25}$ al que le ha dado fuerza la Suprema Corte de Justicia de la Nación en la controversia constitucional 5/2004 y plasmado en la tesis jurisprudencial plenaria número 46/2004 de rubro: "RECURSOS FEDERALES A LOS MUNICIPIOS. CONFORME AL PRINCIPIO DE INTEGRIDAD DE SUS RECURSOS ECONOMICOS, LA ENTREGA EXTEMPORANEA GENERA INTERESES”, es el de integridad de los recursos económicos municipales, que asegura a los municipios la percepción efectiva y puntual de los recursos a que constitucionalmente tienen derecho -con independencia de que sólo algunos de ellos caigan bajo el régimen de libre administración municipal- y que obliga a los estados a pagar los intereses correspondientes cuando retarden la entrega de recursos federales a los municipios.

IV. Los municipios administrarán libremente su hacienda, la cual se formará de los rendimientos de los bienes que les pertenezcan, así como de las contribuciones y otros ingresos que las legislaturas establezcan a su favor, y en todo caso:

a) Percibirán las contribuciones, incluyendo tasas adicionales, que establezcan los Estados sobre la propiedad inmobiliaria, de su fraccionamiento, división, consolidación, traslación y mejora así como las que tengan por base el cambio de valor de los inmuebles.

Los municipios podrán celebrar convenios con el Estado para que éste se haga cargo de algunas de las funciones relacionadas con la administración de esas contribuciones.

b) Las participaciones federales, que serán cubiertas por la Federación a los Municipios con arreglo a las bases, montos y plazos que anualmente se determinen por las Legislaturas de los Estados.

c) Los ingresos derivados de la prestación de servicios públicos a su cargo.

Las leyes federales no limitarán la facultad de los Estados para establecer las contribuciones a que se refieren los incisos a) y c), ni concederán exenciones en relación con las mismas. Las leyes estatales no establecerán exenciones o subsidios en favor de persona o institución alguna respecto de dichas contribuciones. ${ }^{26}$ Sólo estarán exentos los bienes de dominio público de la Federación, de los Estados o los Municipios, salvo que tales bienes sean utilizados por entidades paraestatales o por particulares, bajo cualquier título, para fines administrativos o propósitos distintos a los de su objeto público. ${ }^{27}$

\footnotetext{
${ }^{25}$ González, Arturo, Las Garantías Económico Financieras de la Hacienda Municipal. en: Revista Hacienda Municipal, México, INDETEC, 2007, No. 90, p. 27.

${ }^{26}$ Resulta evidente que el municipio no esta facultado para otorgar exención o subsidio alguno, situación comprensible si aplicamos el criterio de Giuliani que en su obra, afirma: "una consecuencia inevitable del poder gravar es la potestad de desgravar o eximir la carga tributaria”.

${ }^{27}$ Para González, "Este principio es acogido ampliamente por la Ley General de Bienes Nacionales, en donde el criterio clasificador de los bienes propiedad de la Federación depende primordialmente del destino a que se encuentre afecto el bien en específico, esto es, su afectación a alguno de los fines componentes del dominio público, así resulta claro de la lectura de los artículos 6 y 7 del anterior cuerpo normativo, que fue publicado el 22 de mayo de 2004. Así, aún cuando resulta claro que el artículo 115 de la Constitución Federal no prevé una exención por la naturaleza del bien raíz, sino que también considera su utilización para fines públicos”.
} 
Los ayuntamientos, en el ámbito de su competencia, propondrán a las legislaturas estatales las cuotas y tarifas aplicables a impuestos, derechos, contribuciones de mejoras y las tablas de valores unitarios de suelo y construcciones que sirvan de base para el cobro de las contribuciones sobre la propiedad inmobiliaria.

Las legislaturas de los Estados aprobarán las leyes de ingresos de los municipios, revisarán y fiscalizarán sus cuentas públicas. Los presupuestos de egresos serán aprobados por los ayuntamientos con base en sus ingresos disponibles.

Los recursos que integran la hacienda municipal serán ejercidos en forma directa por los ayuntamientos, o bien, por quien ellos autoricen, conforme a la ley.

El artículo en comento, contempla la libertad que el municipio tiene, sobre el manejo de su hacienda pública, en su fracción IV inciso a) se menciona, la posibilidad del establecimiento de impuestos a la propiedad inmobiliaria y cambio del valor de los inmuebles, -facultad que da origen al estudio- previa propuesta de los ayuntamientos, al congreso de la entidad federativa que corresponda. El texto del artículo señala también, el establecimiento de tablas de valores unitarios, de suelo y construcciones que sirven de base para el cobro del predial, la obligación de elaborar y aprobar el presupuesto de egresos y la revisión y fiscalización de las cuentas públicas municipales.

Por otra parte, en México no se comprenderían, las limitaciones de potestad de gobiernos subnacionales en materia fiscal y la armonización de las relaciones fiscales intergubernamentales, sin la presencia del Sistema Nacional de Coordinación Fiscal Federal (SNCF), que se sustenta en la Ley de Coordinación Fiscal (LCF) que el propio congreso expide. Tampoco sería posible entender la hacienda pública municipal, sin la presencia de las participaciones y aportaciones federales, por lo que resulta indispensable el análisis de las facultades que en materia hacendaria tiene el Congreso de la Unión. ${ }^{28}$

Por último, producto de la actual geografía política del país, es de suponerse la existencia de permanentes conflictos entre órdenes de gobierno, particularmente en ámbitos como el financiero. Es común ver, al frente de la administración pública federal un miembro de un determinado partido político, la Estatal por otro y la municipal por uno diferente a los anteriores. Aún cuando la teoría política señala, que al momento de ser gobierno se debe gobernar para todos, sin distinción de partidos en la práctica esto no se da, ya que se privilegia al estado o municipio, que tiene como origen, el mismo partido.

En materia de hacienda pública municipal, son cada vez más frecuentes los escenarios anteriores, ya que los ayuntamientos al agotar la capacidad de gestión política -que frecuentemente no es mucha-, se tenga que acudir a instancias jurídicas que permitan dirimir los conflictos y para tal efecto la Carta Magna ofrece como alternativa, la Controversia Constitucional debidamente regulada en el artículo105 que a la letra dice:

La Suprema Corte de Justicia de la Nación conocerá, en los términos que señale la ley reglamentaria, de los asuntos siguientes:

\footnotetext{
${ }^{28}$ Otro aspecto también relevante de las finanzas públicas, lo constituye la vigilancia sobre la gestión, control y evaluación del presupuesto público federal, del cual forma parte de manera importante el municipio, por lo que será sujeto al cumplimiento de las leyes que sobre la materia expida el Congreso de la Unión. Por último, la optimización de la administración pública requiere de la armonización de sus registros contables, que regirán la contabilidad pública y la presentación homogénea de información financiera, de ingresos y egresos, así como patrimonial, para la Federación, los estados, los municipios y el Distrito Federal (DF), por lo que nuevamente es el Congreso de la Unión el responsable, en uso de las facultades del articulo que en lo conducente, a continuación se transcribe.
} 
I. De las controversias constitucionales que, con excepción de las que se refieran a la materia electoral y a lo establecido en el artículo 46 de esta Constitución, se susciten entre: ${ }^{29}$

a)...; b) La Federación y un municipio; c); d); e);... f) El Distrito Federal y un municipio; g) Dos municipios de diversos Estados; h)...; i) Un Estado y uno de sus municipios, sobre la constitucionalidad de sus actos o disposiciones generales; j) Un Estado y un municipio de otro Estado, sobre la constitucionalidad de sus actos o disposiciones generales; yk)...

Siempre que las controversias versen sobre disposiciones generales de los Estados o de los municipios impugnadas por la Federación, de los municipios impugnadas por los Estados, o en los casos a que se refieren los incisos c), h) y k) anteriores, y la resolución de la Suprema Corte de Justicia las declare inválidas, dicha resolución tendrá efectos generales cuando hubiera sido aprobada por una mayoría de por lo menos ocho votos.

En los demás casos, las resoluciones de la Suprema Corte de Justicia tendrán efectos únicamente respecto de las partes en la controversia.

Este precepto constitucional esta reglamentado por el articulo 11 frac., I, II, III y IV de la Ley Orgánica del Poder Judicial de la Federación (LOPJF) así como por el artículo 12 de la Ley de Coordinación Fiscal, -que como ya se señaló-fue promulgada el 22 de diciembre de 1978 y entró en vigor el primero de enero de 1980, ambos ordenamientos otorgan competencia para conocer de las propias controversias, al pleno de la Suprema Corte de Justicia de la Nación (SCJN).

Es pertinente comentar que el artículo en comento, se encuentra inspirado en el tercero, sección segunda, fracciones I y II de la Constitución de los Estados Unidos de 1787; precepto que también ha sido recogido en sus aspectos generales por los restantes países latinoamericanos que han conservado la estructura federal -Argentina, Brasil y Venezuela-, ya que esta institución está dirigida esencialmente a preservar los límites que la Constitución establece entre las facultades de los organismos centrales y los de carácter local.

\section{LEY DE COORDINACIÓN FISCAL COMENTARIOS PREVIOS}

Desde principios del siglo XX, en México se le fue dando forma a un sistema de coordinación fiscal, a partir de las tres reuniones nacionales fiscales que pretendieron dar orden, al entramado jurídico que en materia impositiva provenía del siglo XIX, pasando por 1947, cuando se expide la Ley del Impuesto sobre Ingresos Mercantiles, y particularmente a partir de 1978, con la expedición de la Ley de Coordinación Fiscal (LCF) en comento, que es finalmente, el documento que se pretende analizar en este epígrafe, partiendo del análisis de su estructura. La LCF en México, constituye el instrumento jurídico que permite armonizar, las relaciones fiscales intergubernamentales y como es natural, resolver los conflictos relacionados con la

\footnotetext{
${ }^{29} \mathrm{El}$ antecedente inmediato del precepto constitucional vigente, se encuentra en el artículo 98 de la constitución del 5 de febrero de 1857, de acuerdo con el cual "corresponde a la Suprema Corte de Justicia desde la primera instancia, el conocimiento de las controversias que se susciten de un estado con otro, y de aquellas que en la Unión fuere parte". Fix-Zamudio, Héctor, Anuario Jurídico, Las garantías constitucionales en el derecho mexicano, (III-IV) México, 1976-1977, p. 736.
} 
concurrencia ${ }^{30}$ propia del modelo de organización política federal, consignado en el articulo 40 de la ley suprema. No obstante, a sus más de 27 años de vigencia y múltiples reformas, resulta innegable la necesidad de su modernización integral o su abrogación, sustituyéndola por una ley de coordinación hacendaria.

La materia relacionada con la coordinación fiscal, por sí misma es complicada, porque involucra a tres órdenes de gobierno y se somete a diferentes arreglos políticos y financieros, entre la Federación, las entidades federativas y los municipios. Los escenarios anteriores se hicieron más complejos a partir del proceso de transición democrática y las tendencias descentralizadoras observadas en el país, llevando a entidades federativas y municipios a reclamar mayores recursos. Porque según señalan, la mayor autonomía política y administrativa, se debe traducir en mayor autonomía económica.

No obstante, el verdadero problema radica en que los ingresos y sus fuentes, con frecuencia son limitados y el requerimiento social creciente, por lo tanto, la demanda de mayores recursos debe llevar siempre consigo, la transferencia de mayores responsabilidades de gasto público. Por último, -como ya se dijo- en México el poder tributario federal se encuentra establecido en los artículos de la CPEUM: 3173 y 131, y la potestad tributaria de las entidades federativas, en los artículos constitucionales 115, 117, 118, 124 y 131. Existen adicionalmente, contribuciones de carácter municipal establecidas por las legislaturas de las entidades federativas, en uso de las facultades que la propia constitución federal les reconoce.

\section{ESTRUCTURA}

LEY DE COORDINACION FISCAL

\section{CAPÍTULO I}

\section{DE LAS PARTICIPACIONES DE LOS ESTADOS, MUNICIPIOS Y} DISTRITO FEDERAL EN INGRESOS FEDERALES

El objeto de la Ley es crear el Sistema Nacional de Coordinación Fiscal, en lo sucesivo SNCF, en razón del cual la Federación entrega a las entidades federativas algunos porcentajes de los impuestos federales denominados "participaciones federales", a cambio de que éstos deroguen o suspendan el cobro de impuestos locales referidos sobre las mismas fuentes gravadas, a fin de evitar la múltiple tributación. ${ }^{31} \mathrm{~A}$ su vez, las legislaturas locales establecen su distribución entre los municipios, en la mayoría de los casos, mediante leyes estatales de coordinación fiscal estatal, y en los demás casos en su legislación fiscal

\footnotetext{
${ }^{30}$ Desde el punto de vista de la competencia tributaria, el tema de la concurrencia impositiva tiene relación con el federalismo fiscal. En un sistema en el que existe concurrencia impositiva de la federación y las entidades federativas, son evidentes las posibles complicaciones tanto para los contribuyentes, como para las propias autoridades tributarias y el Estado. Esto implica que no sólo la existencia de un ejercicio de la competencia tributaria, sino, la posibilidad de que funciones de gestión de contribuciones federales, sean realizadas por autoridades estatales o municipales.

${ }^{31}$ Tanto el Congreso de la Unión como las legislaturas locales, pueden establecer contribuciones sobre las fuentes de ingreso más importantes, por tener facultades coincidentes, razón por la cual, el legislador estableció la celebración de convenios de coordinación fiscal, en términos de lo dispuesto por la ley y el Decreto del Presupuesto de Egresos de la Federación.
} 


\section{CAPÍTULO II}

DEL SISTEMA NACIONAL DE COORDINACIÓN FISCAL

La adhesión al SNCF tienen por objeto, por un lado, armonizar el ejercicio de la potestad tributaria entre los órganos legislativos de la Federación y de las entidades federativas con el fin de evitar la doble o múltiple tributación, ya que las entidades que celebran tales convenios, deben renunciar a establecer las contribuciones que graven hechos o actos jurídicos gravados por la Federación o a suspender la vigencia de los mismos y por otro lado, otorgar a las entidades y a los municipios participaciones respecto de los impuestos recaudados por la Federación. ${ }^{32}$ Consecuentemente, los convenios son aprobados por las legislaturas locales.

Los convenios de adhesión al SNCF no tienen fundamento expreso en la Constitución federal. De hecho, en ellos únicamente se alude al artículo 31, fracción IV, de la Ley Orgánica de la Administración Pública Federal (LOAPF); y a los artículos 2º 10, 11 y 12 de la LCF. Sin embargo, la fracción VII del artículo 116 de la Constitución Política de los Estados Unidos Mexicanos dispone, desde 1987 que "la Federación y los estados, en los términos de ley, podrán convenir la asunción por parte de éstos del ejercicio de sus funciones, la ejecución y operación de obras y la prestación de servicios públicos, cuando el desarrollo económico y social lo haga necesario"."33

Los convenios de adhesión se suscribieron en el año de 1979, un año después de la publicación de la LCF (1978) y uno antes de su entrada en vigor (1980), pero han sufrido diversas modificaciones, particularmente en sus anexos. En sus considerandos, los convenios de adhesión refieren como motivo fundamentalmente, que el sistema nacional fiscal debe ser armónico, evitando en lo posible la superposición de gravámenes federales, estatales y municipales -concurrencia-, cuyo conjunto puede producir cargas fiscales excesivas en los contribuyentes, además de múltiples intervenciones de vigilancia por parte de las diversas autoridades en esta materia.

\section{CAPÍTULO III}

DE LA COLABORACIÓN ADMINISTRATIVA ENTRE LAS ENTIDADES Y LA FEDERACIÓN

Los convenios de colaboración administrativa en materia fiscal federal, establecen las bases para la colaboración fiscal entre la Federación y una entidad federativa, disponiendo que las funciones de administración de las autoridades fiscales federales, se asuman por parte de las autoridades fiscales de las entidades federativas. Los convenios de colaboración no tienen referente expreso en la CPEUM, salvo lo dispuesto por el artículo 116, fracción VII. Sin embargo, cabe preguntarse si las funciones de fiscalización corresponden a la prestación de servicios públicos, ya que, de lo contrario, no existiría facultad alguna a cargo del Poder Ejecutivo Federal para celebrarlos.

“...una actividad técnica encaminada a satisfacer necesidades colectivas básicas o fundamentales, mediante prestaciones individualizadas, sujetas a un régimen de derecho

\footnotetext{
$3^{2}$ Soportado en la tesis: COORDINACIÓN FISCAL ENTRE LA FEDERACIÓN Y LOS ESTADOS. EVOLUCIÓN DE LA REGULACIÓN DE LOS CONVENIOS QUE PARA TAL FIN SE HAN CELEBRADO A PARTIR DEL MARCO CONSTITUCIONAL VIGENTE. Fuente: Semanario Judicial de la Federación y su Gaceta, tomo XII, diciembre de 2000, tesis $2^{\text {a }}$ CLXIX/20oo, p. 432.

${ }^{33}$ Mora, Jorge, Ley de Coordinación Fiscal Comentada, México, Centro de producción editorial, 2004 , p. 17. 
público, que determina los principios de regularidad, uniformidad, adecuación e igualdad. Esta actividad puede ser prestada por el Estado o por los particulares (mediante concesión)" ${ }^{34}$ De lo anterior se deduce que los actos de fiscalización que llevan a cabo las autoridades administrativas para revisar la situación fiscal de los contribuyentes y, en su caso, determinar créditos fiscales federales, no corresponden a una actividad que constituye una necesidad colectiva básica; es decir, no es un servicio público.

\section{CAPÍTULO IV}

DE LOS ORGANISMOS EN MATERIA DE COORDINACIÓN

\section{I.- La Reunión Nacional de Funcionarios Fiscales}

Según el artículo $3^{\circ}$ del Reglamento Interior de los Organismos del Sistema Nacional de Coordinación Fiscal, aprobado en la XXVI Reunión Nacional de Funcionarios Fiscales en junio de 1994, "la Reunión (RNFF) es el órgano supremo del sistema a través del cual los funcionarios fiscales proponen, discuten y en su caso, aprueban los lineamientos para el desarrollo permanente y perfeccionamiento del mismo".

II.- La Comisión Permanente de Funcionarios Fiscales

Entre la facultades más importantes de la CPFF se encuentran, preparar las Reunión Nacional de Funcionarios Fiscales (RNFF), los proyectos de distribución de aportaciones para los órganos del SNCF; fungir como Consejo Directivo del INDETEC; vigilar la creación e incremento de los fondos de ley, su distribución y las liquidaciones anuales; vigilar la determinación, liquidación y pago de participaciones a los municipios; ${ }^{35} \mathrm{y}$ formular los dictámenes técnicos relativos a la presunta violación de los artículos 73, fracción XXIX; 117, fracciones IV a VII y IX; o 118, fracción I, de la Constitución federal por una entidad, o bien, la falta de cumplimiento de los convenios de coordinación fiscal o de colaboración administrativa en materia fiscal federal.

III.- El Instituto para el Desarrollo Técnico de las Haciendas Públicas (INDETEC).

Sus funciones más importantes son la realización de estudios relativos al SNCF y de la legislación tributaria federal y de las entidades, así como de sus administraciones, incluso en forma remunerada; proponer medidas de coordinación de acciones entre unos y otros; fungir como Secretaría Técnica de la Reunión Nacional y de la Comisión Permanente de Funcionarios Fiscales; actuar como consultor técnico y promotor de las haciendas públicas; capacitar y desarrollar los programas de la RNFF. ${ }^{36}$

IV.- La Junta de Coordinación Fiscal

La Junta de Coordinación Fiscal, se integra por los representantes de la Secretaria de Hacienda y Crédito Público y los titulares de los órganos hacendarios de las ocho entidades que forman la Comisión Permanente de Funcionarios Fiscales, se creó en 1990 y es el organismo del Sistema Nacional de Coordinación Fiscal, responsable de elaborar dictámenes técnicos, a solicitud de la SHCP en relación con los recursos de inconformidad presentados por las

34 Giusti, Miguel, Alas y raíces: ensayos sobre ética y modernidad, Lima, PUCP, 1999, p. 774.

${ }^{35}$ Con objeto de reglamentar la facultad de la CPFF relativa a la vigilancia del sistema de participaciones, en septiembre de 2000, la CLIX Reunión de la Comisión Permanente de Funcionarios Fiscales aprobó el Reglamento del Comité de Vigilancia del Sistema de Participaciones en Ingresos Federales.

${ }^{36}$ Se constituyó en 1973 como una asociación civil, y como un organismo público descentralizado a partir de 1980, con la entrada en vigor de la LCF. Su patrimonio se constituye con aportaciones de la SHCP y de las entidades federativas. 
personas que se consideren afectadas, por incumplimiento de las disposiciones del SNCF y de las de coordinación en materia de derechos.

\section{CAPITULO V}

DE LOS FONDOS DE APORTACIONES FEDERALES

La figura de los fondos de aportaciones se introdujo en la reforma fiscal para 1998, a propuesta de la $\mathrm{SHCP},{ }^{37}$ a fin de establecer nuevos mecanismos para descentralizar el gasto público federal a través de la transferencia de recursos y responsabilidades a los estados y municipios, apoyos que hasta entonces se canalizaban vía convenios de coordinación con los gobiernos estatales, - es de ponderarse desde la creación de los fondos de aportaciones se ha observado un importante crecimiento en el gasto que ejercen directamente las entidades federativas y municipios-.

Estos fondos son de naturaleza federal y corresponden a una partida que la Federación destina para coadyuvar al fortalecimiento de los estados y municipios en apoyo de actividades específicas; se prevén en el Presupuesto de Egresos de la Federación (PEF), se regulan en el capítulo V de la LCF, y resultan independientes de los que se destinan a los estados y municipios por concepto de participaciones federales.

I. Fondo de Aportaciones para la Educación Básica y Normal;

II. Fondo de Aportaciones para los Servicios de Salud;

III. Fondo de Aportaciones para la Infraestructura Social;

IV. Fondo de Aportaciones para el Fortalecimiento de los Municipios y de las Demarcaciones Territoriales del Distrito Federal;

V. Fondo de Aportaciones Múltiples;

VI.- Fondo de Aportaciones para la Educación Tecnológica y de Adultos;

VII.- Fondo de Aportaciones para la Seguridad Pública de los Estados y del Distrito Federal; y

VIII.- Fondo de Aportaciones para el Fortalecimiento de las Entidades Federativas.

\section{EN LA LEGISLACIÓN ESTATAL. ${ }^{38}$}

En materia de ingresos públicos municipales, las entidades federativas cuentan con una legislación similar o equivalente entre si, por lo que -como ya se dijo- para efectos del estudio, se tomara a manera de ejemplo, la vigente al momento de realizar la investigación, en el Estado de Jalisco que entre otras, las de mayor relevancia por su relación directa con el ingreso se encuentran:

\footnotetext{
${ }^{37}$ La propuesta de la SHCP únicamente incluyó los fondos en materia de educación básica y normal (FAEB); de salud (FASS); y para el desarrollo de la infraestructura social básica en los municipios marginados (FISM). Sin embargo, afortunadamente, la reforma contó con la intervención de los partidos políticos de oposición. De esta manera, el FISM fue modificado en una negociación entre el Partido Revolucionario Institucional y el Partido de Acción Nacional para establecer, en vez de este fondo, otros tres: el Fondo de Aportaciones para la Infraestructura Social (FAIS), constituido, a su vez, por dos más: el Fondo para la Infraestructura Social Municipal (FAISM) y el Fondo de Aportaciones para la Infraestructura Social Estatal (FAISE); el Fondo de Aportaciones para el Fortalecimiento de los Municipios y del Distrito Federal (Fortamun); y el Fondo de Aportaciones Múltiples (FAM).

${ }^{38}$ Se toma como base la legislación del Estado de Jalisco para efectos del estudio. 
- Constitución Política del Estado de Jalisco

- Ley de Planeación para el Estado de Jalisco y sus Municipios

- Ley de Desarrollo Urbano del Estado de Jalisco

- Ley de Coordinación Fiscal del Estado de Jalisco con sus Municipios

- Ley de Catastro Municipal del Estado de Jalisco

- Ley de Hacienda Municipal del Estado de Jalisco

\section{CONSTITUCIÓN POLÍTICA DEL ESTADO DE JALISCO}

En materia de soberanía nacional y forma de gobierno -como ya se comentó- son los artículos 39, 40, y 41de la CPEUM, los que regulan la situación de los Estados ante la Federación, por su parte, las entidades federativas -como es el caso de Jalisco-, reconocen la soberanía de su régimen interior y a su ves, ser parte integrante del Estado Federal Mexicano.

Artículo $1^{\circ}$.- El Estado de Jalisco es libre y soberano en su régimen interior, pero unido a las demás partes integrantes de los Estados Unidos Mexicanos, en la Federación establecida por la Ley Fundamental.

El orden que se dará al análisis de la Constitución Política del Estado de Jalisco, es el mismo que se siguió, en la exploración de la Constitución Federal, incorporando al estudio sólo las partes de los artículos que directa o indirectamente, tengan que ver con la potestad recaudatoria municipal. Después que en el artículo primero, Jalisco reconoce ser parte integrante de la Federación, se continuará con el análisis del origen de la obligación que los Jaliscienses ${ }^{39}$ tienen de contribuir al gasto público, compromiso contemplado en el artículo quinto ${ }^{40}$ que a la letra dice:

Las personas físicas o jurídicas, en los términos que señalen las leyes, tendrán la obligación de:

I. Contribuir para los gastos públicos de la manera proporcional y equitativa que dispongan las leyes;

II, III,...

En materia de planeación, el Estado de Jalisco contempla en su Constitución, la obligación de crear el sistema estatal de planeación, en concordancia a lo establecido en el artículo 26 de la Constitución Federal.

Artículo 15.- Los órganos del poder público del Estado proveerán las condiciones para el ejercicio pleno de la libertad de los individuos y grupos que integran la sociedad y pro-

\footnotetext{
39 Son jaliscienses: I. Los nacidos en el territorio del Estado; y II. Los mexicanos por nacimiento o naturalización avecindados en el Estado y que no manifiesten su deseo de conservar su residencia anterior, en la forma que establezca la ley. La vecindad no se pierde por ausencia debida al desempeño de cargos públicos, de elección popular, o en defensa de la patria y de sus instituciones (Artículo $7^{\circ}$ ).

${ }^{40}$ Paralelamente y para dar fuerza a esta obligación, -curiosamente en un artículo que reconoce prerrogativasel articulo octavo señala: Son obligaciones de los ciudadanos jaliscienses, las contenidas en los artículos 31 y 36 de la Constitución Política de los Estados Unidos Mexicanos.
} 
piciarán su participación en la vida social, económica, política y cultural de la entidad. Para ello:

I, II, III, IV, V,...

VI. Las autoridades estatales y municipales, organizarán el sistema estatal de planeación, para que mediante el fomento del desarrollo sustentable y una justa distribución del ingreso y la riqueza se permita a las personas y grupos sociales el ejercicio de sus derechos, cuya seguridad y bienestar protege esta Constitución;

VII, VIII, IX,...

En relación con el poder legislativo del Estado de Jalisco, y su facultad en materia fiscal, -totalmente concordante con lo establecido por el artículo 73-XXIX DE LA CPEUM- la Constitución local señala:

Artículo 35.- Son Facultades del Congreso:

I, II, III,...

IV. Determinar los gastos del Estado para cada ejercicio fiscal, así como las contribuciones del Estado y municipios para cubrirlos, y revisar y fiscalizar las cuentas correspondientes.

De la V a la XXXVI...

En materia de regulación del gobierno municipal la Constitución local de Jalisco, reserva el Titulo Séptimo su regulación.

Artículo 73.-El municipio libre es base de la división territorial y de la organización política y administrativa del Estado de Jalisco, investido de personalidad jurídica y patrimonio propios, con las facultades y limitaciones establecidas en la Constitución Política de los Estados Unidos Mexicanos y los siguientes fundamentos:

I, II, III, IV, V,...

Artículo 80.- Los municipios a través de sus ayuntamientos, en los términos de las leyes federales y estatales relativas, estarán facultados para:

I, II, III, IV, V, VI...

VII. Organizar y conducir la planeación del desarrollo del municipio y establecer los medios para la consulta ciudadana y la participación social;

VIII, IX, X,... 


\section{DE LA HACIENDA Y DEL PATRIMONIO MUNICIPAL}

Artículo 88.- Los municipios administrarán libremente su hacienda, la cual se formará de los rendimientos de los bienes que les pertenezcan, así como de las contribuciones y otros ingresos que el Congreso establezca a su favor y, en todo caso, con:

I. Las contribuciones sobre la propiedad inmobiliaria, incluyendo tasas adicionales que establezca el Congreso, de su fraccionamiento, división, consolidación, translación y mejora.

Los municipios podrán celebrar convenios con el Estado, para que éste se haga cargo de algunas de las funciones relacionadas con la administración de estas contribuciones;

II. Las participaciones federales y estatales que correspondan a los municipios, con arreglo a las bases, montos y plazos que anualmente se determinen por el Congreso del Estado; y

III. Los ingresos derivados de la prestación de servicios públicos a su cargo.

El patrimonio municipal se compondrá con los bienes de dominio público y los bienes de dominio privado, de conformidad con lo que establezca la ley de la materia.

10. LEGISLACIÓN MUNICIPAL BÁSICA

En el estado de Jalisco, además de las leyes ya mencionadas en el epígrafe anterior, en materia de regulación de la hacienda pública municipal, existen otras de aplicación específica como:

Ley del Gobierno y la Administración Pública Municipal del Estado de Jalisco.

Ley de Ingresos de cada uno de los municipios del Estado.

Ley de hacienda Municipal del Estado de Jalisco, entre otras.

Código Fiscal Municipal en algunas entidades federativas -no en Jalisco-.

\section{CONCLUSIONES}

En México, es necesario instrumentar mecanismos que permitan en materia de Relaciones Intergubernamentales, que estas, sean más claras y equitativas, tanto en lo recaudatorio como en la aplicación del gasto. Se debe también, involucrar al municipio en el debate sobre distribución de potestad, situación común entre federación y entidades federativas, pero sólo ocasional entre los tres órdenes de gobierno. Porque la ausencia de una autentica potestad tributaria municipal, ha hecho engañosa la autonomía y equilibrio entre órdenes de gobierno, que tanto se pondera en la exposición de motivos, previa a cada reforma del artículo 115 constitucional.

Como se puede observar, es limitada la potestad recaudatoria de la hacienda municipal y evidente que la mayor parte de los municipios del país, mantienen su recaudación muy por 
debajo de su verdadero potencial. Como justificación de esto último existen dos argumentos: a) que la limitada potestad tributaria en materia inmobiliaria, no se pueden hacer valer con la fuerza necesaria, por las graves carencias de los habitantes en gran parte de los municipios del país, situación que se traducen en incapacidad de pago; y la limitada presencia de recursos humanos capacitados para operar con eficiencia sus tesorerías y catastros, aunque esto último, es perfectamente superable con la figura legalmente aceptada, del acuerdo de colaboración administrativa.

No obstante y aún con las limitaciones anteriores, es necesario actualizar las bases tributarias de los principales gravámenes locales, especialmente del impuesto a la propiedad y los de industria y comercio, los dos con mayor potencial recaudatorio. Paralelo a esto, se debe adelantar una simplificación del marco legal vigente, de tal forma que se agilice y facilite el cobro y recolección de los tributos, se establezcan los procedimientos y normas que permitan hacer cumplir la normatividad de la tributación subnacional, y se logre el control de la evasión y elusión que en la hacienda local, hay casos en que llega a ser casi absoluta.

Por último, con el fin de fortalecer la gestión hacendaria local se pueden identificar acciones orientadas a incrementar los ingresos propios, a través de estrategias y mejores prácticas recaudatorias. Resulta también necesario, capacitar al personal para incrementar la eficiencia en la aplicación del gasto, hacer ajustes en los procesos de presupuestación, transparentar la gestión y rendir cuentas con oportunidad. Porque la gestión hacendaria local eficiente, exige por definición de un manejo con enfoque integral, de sus políticas públicas y fortalecimiento institucional

\section{BIBLIOGRAFÍA}

ACOSTA, Miguel, Teoría general del derecho administrativo, México, Editorial Porrúa, 1999, p.

ARRIAGA, Enrique, Finanzas Públicas de México, México, Instituto Politécnico Nacional, 1992, p. 5.

CARRAL y de TERESA, Luis, Derecho notarial y derecho registral, $4^{a}$ edición, México, Editorial Porrúa, 1978, p. 76.

De la GARZA, Sergio, Derecho Financiero Mexicano, 8va edición, México, Editorial Porrúa, 1978, pág. 52, 198.

DÍAZ, Rosa. "Estudio monográfico acerca de la autonomía y conceptualización del Derecho Financiero, Público o Fiscal”, Tribunal Fiscal de la Federación, cuarenta y cinco años al servicio de México. Tomo I, p. 277.

FAYA, Jacinto, Finanzas Públicas, México, Editorial Porrúa, 1986, p. 39.

FIX-ZAMUDIO, Héctor, Anuario Jurídico, Las garantías constitucionales en el derecho mexicano, (III-IV) México, 1976-1977, p. 736.

, Diccionario Jurídico Mexicano, Tercera edición, México, Instituto de Investigaciones Jurídicas, UNAM, Editorial Porrúa, 1996.

FLORES, Ernesto, Elementos de Finanzas Públicas Mexicanas, México, Editorial Porrúa, 1991, p. 10, 20. 
GARCÍA, Agustín, 1998. Análisis Constitucional de los ámbitos de la federación, los estados y municipios, en: Obra conmemorativa de los 50 años del TFF, México, TFF, 1988, tomo V, p. 89.

GIULIANI, Carlos, Derecho Financiero, Buenos Aires, Editorial Depalma, 1977, Volumen I. GIUSTI, Miguel, Alas y raíces: ensayos sobre ética y modernidad, Lima, PUCP, 1999, p. 774.

GONZÁLEZ, Eusebio, Prologo a la obra: Principios Tributarios Constitucionales, México, coedición UNAM, TFF, Ed. Universidad de Salamanca e instituto Cultural Domecq, 1989, p. 2, 27.

GONZÁLEZ, Arturo, La Exención del Pago de Contribuciones Inmobiliarias en Bienes del Dominio Público, en: Revista Hacienda Municipal, México, INDETEC, 20o8, No. 92.

Las Garantías Económico Financieras de la Hacienda Municipal. en: Revista Hacienda Municipal, México, INDETEC, 2007, No. 90

MARTÍN, José y Rodríguez, Guillermo, Derecho Tributario General, de Finanzas y Derecho Tributario, Argentina, Depalma, 1995.

MORA, Jorge, Ley de Coordinación Fiscal Comentada, México, Centro de producción editorial, 2004, p. 17.

MARGÁIN, Emilio, Introducción al Estudio del Derecho Tributario Mexicano, $4^{\text {a }}$ edición, San Luis Potosí, Universidad Autónoma de San Luis Potosí, 1977, p. 22.

ORTEGA, Juan, Primer Curso de Derecho Tributario Mexicano, México, Editorial Porrúa, 2004, p. 4.

PACHECO, Guillermo, Supremacía Constitucional y Federalismo Jurídico, México, Editorial Porrúa, 2001, p. 73.

QUINTANA, Jesús y Rojas, Jorge, Derecho Tributario Mexicano, México, Editorial Trillas, 1997.

RENDÓN HUERTA, Teresita, Derecho Municipal, Tercera edición, México, Editorial Porrúa, 2005, p. 294.

RODRÍGUEZ, Raúl, Derecho Fiscal, México, Editorial Harla, 1990, p. 11.

\section{LEGISLACIÓN CONSULTADA:}

Constitución Política de los Estados Unidos Mexicanos.

Constitución Política del Estado de Jalisco.

Ley de Coordinación Fiscal (federal).

Ley General de Bienes Nacionales.

Ley de planeación (federal).

Ley de Planeación para el Estado de Jalisco y sus Municipios. 
Ley Orgánica del Poder Judicial de la Federación.

Ley de Desarrollo Urbano del Estado de Jalisco.

Ley de Catastro Municipal del Estado de Jalisco.

Ley de Coordinación Fiscal del Estado de Jalisco con sus Municipios.

Ley de Hacienda Municipal del Estado de Jalisco.

Ley de Fiscalización Superior de la Federación. 